\title{
Match-mismatch dynamics in the Norwegian-Barents Sea system
}

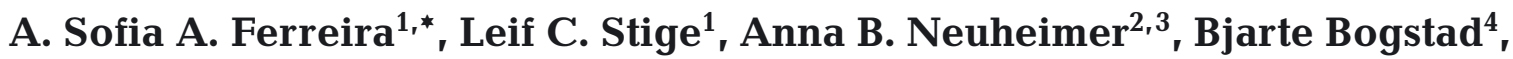 \\ Natalia Yaragina ${ }^{5}$, Irina Prokopchuk ${ }^{5}$, Joël M. Durant ${ }^{1}$ \\ ${ }^{1}$ Centre for Ecological and Evolutionary Synthesis (CEES), Department of Biosciences, University of Oslo, Blindernveien 31, \\ 0371 Oslo, Norway \\ ${ }^{2}$ Department of Oceanography, School of Ocean and Earth Science and Technology, University of Hawai'i at Manoa, \\ Honolulu, HI 96822, USA \\ ${ }^{3}$ Aarhus Institute of Advanced Studies, Aarhus University, 8000 Aarhus C, Denmark \\ ${ }^{4}$ Institute of Marine Research, PO Box 1870 Nordnes, 5817 Bergen, Norway \\ ${ }^{5}$ Polar branch of Russian Federal Research Institute of Fisheries and Oceanography, \\ VNIRO ('PINRO' named after N.M. Knipovich), Knipovich-St. 6, 183038 Murmansk, Russia
}

\begin{abstract}
A key process affecting variation in the recruitment of fish into fisheries is the spatiotemporal overlap between prey and predator (match-mismatch hypothesis, MMH). The Northeast Arctic cod Gadus morhua and its dominant prey, the copepod Calanus finmarchicus, have long been studied in the Norwegian-Barents Sea system. However, the mechanistic explanation of how cod survival is affected by MMH dynamics remains unclear. Most MMH studies have focused on either the time synchrony or the spatial overlap between trophic levels. Here, we used G. morhua larvae and C. finmarchicus data collected in the Norwegian-Barents Sea via ichthyoplankton surveys from 1959-1992 to assess the effect of the predator-prey relationship on predator recruitment to the fisheries at age 3 (as a measure of survival) and to develop a metric of predator-prey overlap using spatio-temporal statistical models. We then compared the interannual variability of the predator-prey overlap with the predator's abundance at recruitment to assess how MMH dynamics explain the survival of cod during its early life stages. We found that the amount of overlap between cod larvae (length: 11-15 mm) and their prey explained $29 \%$ of cod recruitment variability. Positive correlations between predator-prey overlap and subsequent recruitment were also found for predators of $6-10$ and $16-20 \mathrm{~mm}$, but not for $21+\mathrm{mm}$. This improved predator-prey overlap metric is thus (1) useful to better understand how predator-prey dynamics at early life stages of fish impact the survival of later stages; and (2) a valuable tool for assessing the state of an ecosystem.
\end{abstract}

KEY WORDS: Spatial overlap · Phenology · Predator-prey dynamics · Match-mismatch hypothesis · Recruitment variability · Gadus morhua $\cdot$ Calanus finmarchicus

\section{INTRODUCTION}

From the moment fish eggs are spawned until a cohort enters the fishery (recruitment, $R$ ), a wide range of processes affects its survival. Hjort (1914) suggested that the conditions experienced by early life stages of fish can lead to large population-level variations in $R$ and biomass. However, the relative importance of the processes that determine year-

*Corresponding author: asofiaaferreira@gmail.com

$\S$ Advance View was available online April 9, 2020;

subsequently updated April 15, 2020 class strength in many exploited marine populations remains obscure. In general, such processes include starvation, predation, transport to/from favourable habitats, direct physiological effects of abiotic oceanographic conditions and interactions among these processes (Houde 2008). In addition, there is now a large body of evidence that demonstrates how spawning stock biomass and demographic structure can influence $R$ via variations in egg production and

( ) The authors 2020. Open Access under Creative Commons by Attribution Licence. Use, distribution and reproduction are unrestricted. Authors and original publication must be credited. 
quality (Kjesbu et al. 1996, Trippel et al. 1997, Marshall et al. 1998) and how spawner biomass and environmental conditions interact to affect $R$ (Brander \& Mohn 2004, Perry et al. 2010, Planque et al. 2010).

\subsection{Match-mismatch hypothesis}

A key factor influencing variability in $R$ is the effect of spatio-temporal overlap between prey and predator on predator survival. The rationale is that, right after being spawned, high mortality rates are observed in fish early life stages due to either high predation or low food availability. After hatching, fish larvae are sustained by the yolk-sac and, as soon as the yolk-sac is absorbed, they rely on the presence of food in order to survive and grow (Hjort 1914). This critical period - the transition from capital to income energy supply - is associated with variations in both physical and biological factors, thus affecting the survival of many fish species (Hjort 1914). In the same publication, Hjort (1914, p. 205) first introduced the idea that a mismatch in the period 'when the young larvae first require extraneous nourishment, and the period when such nourishment is first available' could lead to higher mortality. In the late 1960s, however, Cushing introduced a mechanism to explain the variability of the mortality linked to this critical period (Cushing 1967). This mechanism was further refined in 1990, where he stated that a key factor in determining the survival of larval fish is the match (or mismatch) between the timing of the period when larvae feed on plankton and the timing of the plankton peak production (Cushing 1990).

In short, if there is a match (high overlap), the probability of larvae surviving onto the next life stage will be higher. Larvae experiencing favourable conditions may experience less predation due to faster growth (Hjort 1914, Cushing 1967, 1990, Fortier et al. 1995, Durant et al. 2007). Conversely, when there is a mismatch, larvae are less likely to survive. Despite limited empirical data, there have been some studies supporting this hypothesis (e.g. Leggett \& Deblois 1994, Platt et al. 2003, Koeller et al. 2009, Kristiansen et al. 2011, Durant et al. 2013).

\subsection{Match-mismatch dynamics in the Norwegian-Barents Sea system}

The Norwegian-Barents Sea system is an area with highly dynamic physical and biological forcing (Sakshaug et al. 2009), where the Northeast Arctic cod Gadus morhua is a major predator and one of the most abundant fish species in the region. The Northeast Arctic cod spawns along the Norwegian coast; the eggs and the larvae spread northwards and eastwards, where the newly hatched larvae feed on an omnivorous diet (Vikebø et al. 2007, Bogstad et al. 2016). The most dominant zooplankton species in the Norwegian-Barents Sea system is the copepod Calanus finmarchicus (Melle et al. 2004, Eiane \& Tande 2009, Orlova et al. 2010). In this region, C. finmarchicus goes through 6 nauplii stages (NI-NVI), 5 copepodite stages (CI-CV) and one adult stage (CVI, that can be either male or female) within 1 yr or less (Eiane \& Tande 2009). C. finmarchicus is the main food item in the diet of many fish species, including the larvae of the Northeast Arctic cod (Ellertsen et al. 1987, Vikebø et al. 2007). In this study, we coupled $G$. morhua as the predator and $C$. finmarchicus as the prey to assess the effect of the spatio-temporal overlap between prey and predator on predator survival. We did this by developing a metric that acknowledges the roles of mismatch in both space and time. In order to identify the influence of the match-mismatch hypothesis (MMH) on the predator-prey coupling, one needs to quantify an overlap between predator and prey in time and space, and that overlap needs to be correlated with the $R$ of the predator.

\subsection{MMH metrics}

MMH studies not only provide information on the ecosystem state by assessing species abundance and composition (Durant et al. 2007), they also provide a link between the different marine trophic levels (through energy transfer; Edwards \& Richardson 2004). However, many of those studies fail to provide information on the mechanistic applicability of $\mathrm{MMH}$ in space. While there are several timing/phenology indicators (Yoder \& Kennelly 2003, Platt \& Sathyendranath 2008, Cole et al. 2015), spatial indicators are less common due to the lack of highly resolved spatial data, which leads to the role of space being ignored in $\mathrm{MMH}$ studies. As noted by Carroll et al. (2019), acknowledging space in overlap metrics is essential, as the spatial resolution at which predatorprey interactions are important is often ignored. This can then influence how one interprets the dynamics of both predator and prey within their ecosystem. In this particular coupling (G. morhua and C. finmarchicus), space may play an important role that previous MMH studies may have missed (Helle 1994, 2000, Helle \& Pennington 1999). 
In addition to acknowledging space, an overlap metric should allow for the possibility of a mismatch occurring (Durant et al. 2007). A mismatch occurs whenever the degree of temporal and spatial overlap between prey and predator production limits the predator's survival. Therefore, in order to explore the role of the joint spatio-temporal effect of mismatch on survival of predator fish, there must be a metric that acknowledges the roles of mismatch in both space and time.

Other phenology metrics have been widely used to assess the state of an ecosystem. As distinguished by Ferreira et al. (2014), phenology metrics differ from phenology indicators in that the former are realworld estimators of the latter (see detailed definitions in Ferreira et al. 2014). The most common indicators are the timing of the peak density (e.g. Yoder \& Kennelly 2003) and the timing of initiation (e.g. Siegel et al. 2002), whereas metrics are the different mathematical formulations one uses to estimate the indicators. For instance, there are several metrics used to calculate the timing of initiation (an indicator), such as the ones used in this study. Here, we estimated 6 metrics for each larval size class: prey amplitude, prey magnitude, peak timing, timing of initiation, maximum growth rate and predator-prey overlap (see Table 2 for definitions). The first 5 metrics include those most commonly used in the literature (Ji et al. 2010), to which we added our newly developed metric of overlap.

\section{MATERIALS AND METHODS}

In order to successfully test whether $\mathrm{MMH}$ explains $R$ of the Northeast Arctic cod, we needed to have a gap-free (i.e. no missing data), low-noise data set. Therefore, we modelled both predator and prey abundance changes over space and time to fill gaps in the observations and reduce noise (Kvile et al. 2014, Stige et al. 2017). These spatio-temporal models for Northeast Arctic cod and copepod both use information on the temperature experienced by the organisms at the time and place they were sampled (Kvile et al. 2014, Stige et al. 2017).

\subsection{Zoo- and ichthyoplankton data}

Data on copepod Calanus finmarchicus and Northeast Arctic cod Gadus morhua larvae were collected during the ichthyoplankton surveys run by the Knipovich Polar Research Institute of Marine Fish- eries and Oceanography (PINRO) in both spring (April-May) and summer (June-July) by using a Juday plankton net (copepods: $37 \mathrm{~cm}$ diameter opening, $180 \mu \mathrm{m}$ mesh size) and an egg net and ring trawl (fish larvae: $80 \mathrm{~cm}$ diameter opening, $0.505 \mathrm{~mm}$ mesh size and $150 \mathrm{~cm}$ diameter opening, $3 \mathrm{~mm}$ mesh size; Nesterova 1990, Mukhina et al. 2003, respectively). Sampling covered the northeastern Norwegian Sea and the southwestern Barents Sea from 1959-1992 (Fig. 1, with 1966, 1980, 1981, 1986, and 1990 missing). We focused on data collected in the upper $50 \mathrm{~m}$. For G. morhua larvae, we used data collected with both ring trawl and egg net, thus excluding stations in which only one method was used. While larvae are also captured in egg nets, the egg nets sample larvae less efficiently than the ring trawls, and the observation noise was expected to be higher for stations with only egg net samples. Both $C$. finmarchicus and $G$. morhua abundance data were recorded as ind. $\mathrm{m}^{-3}$ for each size class. From this point, we will refer to abundance or biomass per $\mathrm{m}^{3}$ (technically concentrations) as simply abundance or biomass.

In this study, we binned $C$. finmarchicus stages into 4 stage classes as follows: nauplii, CI-CIII, CIV-CV and CVI male and female. The reason for this division is 2-fold: it characterises the cod diet preferences per larval fish size class, and the copepod data is not resolved enough to consider each copepod stage individually. Copepod nauplii stages were only identified as Calanus sp. (Nesterova 1990). Further description of the data on $C$. finmarchicus can be found in Kvile et al. (2014).

Data on G. morhua larvae were zero-inflated (see Figs. S1 \& S2 in the Supplement at www.int-res.com/ articles/suppl/m650p081_supp.pdf). For this study, we only considered the feeding size classes of G. morhua, which start at around 4.5-5.2 mm (Bjørke \& Sundby 1984). The available larval data were divided into length classes, thus limiting us to start the feeding size classes at $6 \mathrm{~mm}$. We kept the remaining size classes as per the original data set: L2 (6-10 mm), L3 (11$15 \mathrm{~mm}), \mathrm{L} 4(16-20 \mathrm{~mm})$ and L5 (21+ mm). We used standard length (SL) to calculate gape size (GS) of the larval cod, following Rowlands et al. (2006): GS = $\left(\mathrm{SL}^{1.376}\right) \times 5.297 \times 10^{-2}($ for $\mathrm{SL}<10.56 \mathrm{~mm})$, and $\mathrm{GS}=$ $\left(\mathrm{SL}^{0.768}\right) \times 2.952 \times 10^{-1}($ for $\mathrm{SL}>10.56 \mathrm{~mm}) ;$ Table 1 provides definitions for all variables used in this study. These estimates allowed us to calculate the size class of copepods that each larval size class eats, by using copepod lengths per stage calculated by Campbell et al. (2001; reared at $8^{\circ} \mathrm{C}$ in the laboratory), as follows: L2 size class of $G$. morhua eats up to stage CIII of $C$. finmarchicus $(1.36 \mathrm{~mm}), \mathrm{L} 3$ eats up to stage CV $(2.37 \mathrm{~mm})$, 


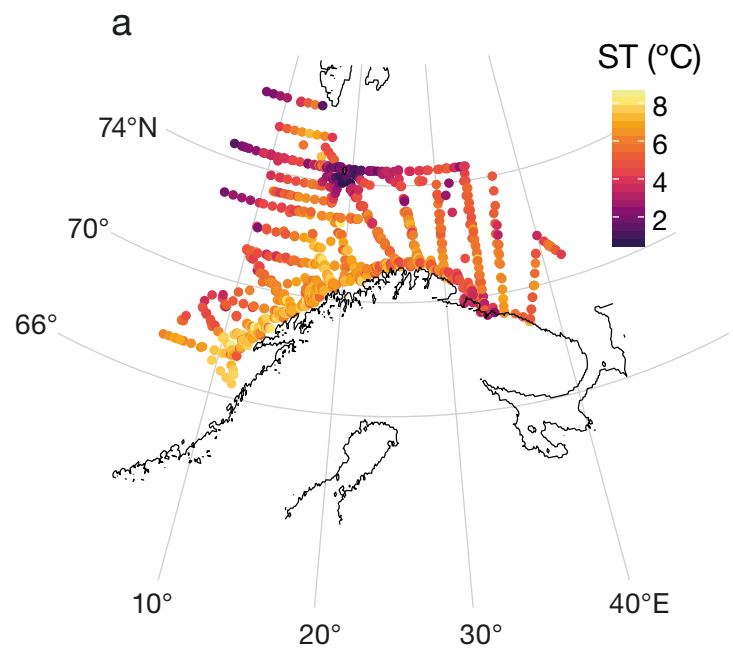

b
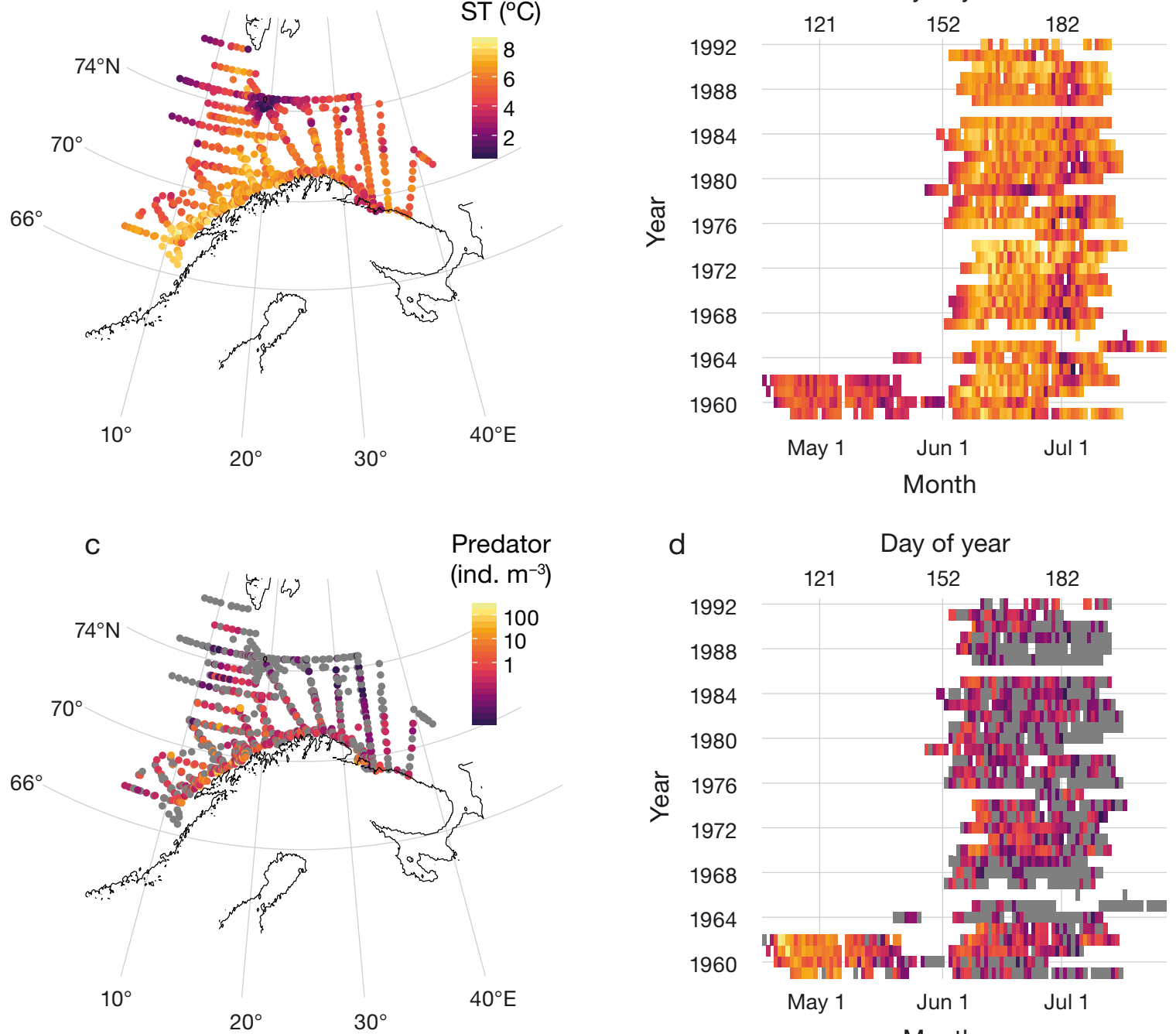

d
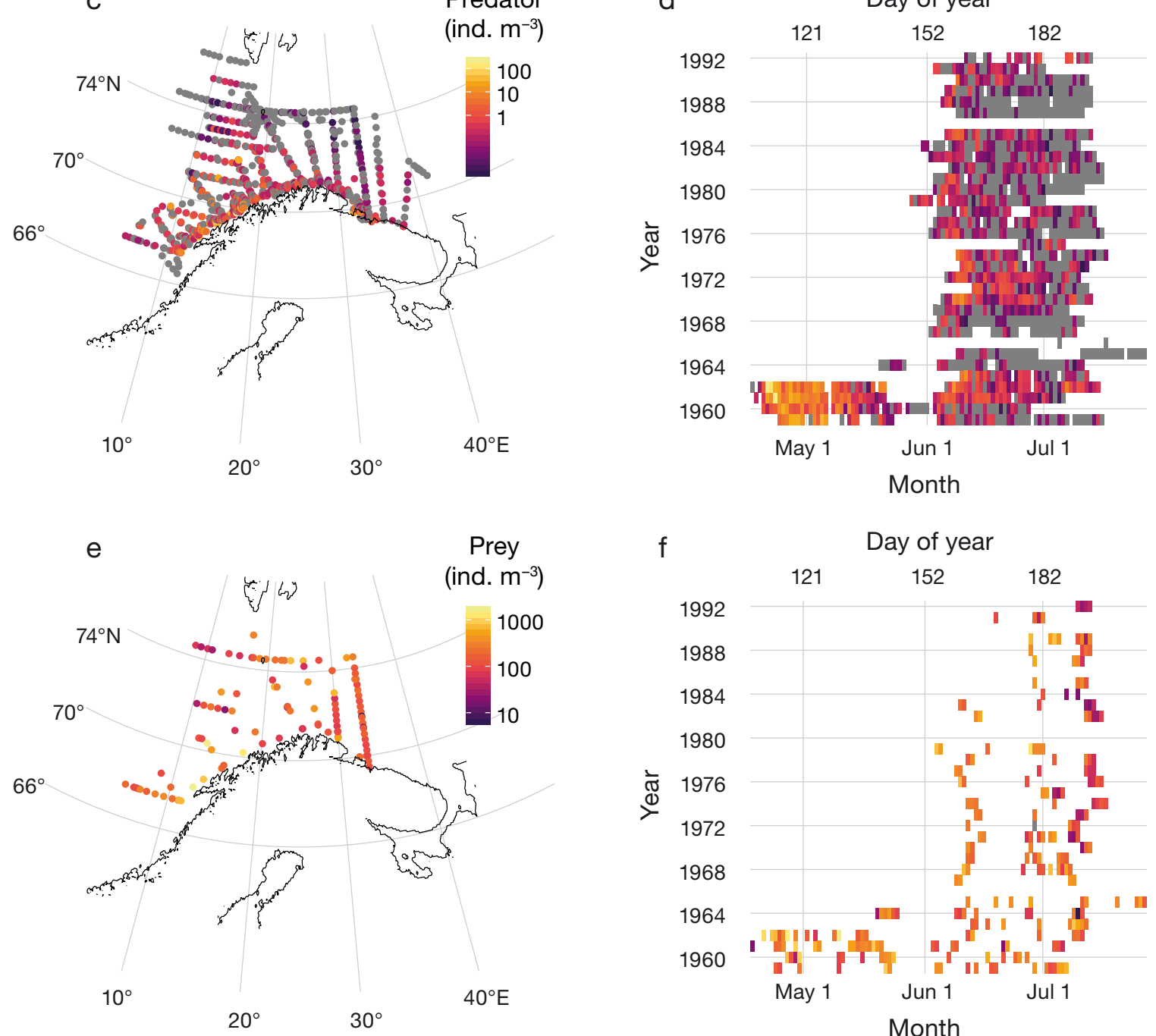

Fig. 1. (a,c,e) Spatial and (b,d,f) temporal distributions of sea temperature (ST; a,b), Gadus morhua larvae (c,d) and Calanus finmarchicus $(\mathrm{e}, \mathrm{f})$ of all size classes and stage classes, respectively. Grey shading indicates presence of zeros 
Table 1. Acronyms used in this study. Predator: Gadus morhua larvae (indicated by $L$ ); prey: Calanus finmarchicus (indicated by $Z$ as in zooplankton)

\begin{tabular}{|c|c|}
\hline Acronym & Description \\
\hline $\mathrm{MMH}$ & Match-mismatch hypothesis \\
\hline$R$ & Predator recruitment (age 3) \\
\hline GS & Predator gape size \\
\hline SL & Predator standard length \\
\hline$i$ & $\begin{array}{l}\text { Prey stage class (nauplii, CI-CIII, CIV-CV, } \\
\text { adults) }\end{array}$ \\
\hline$j$ & Predator size class (L2, L3, L4 and L5) \\
\hline$Z$ & Prey abundance or biomass \\
\hline$L$ & Predator abundance \\
\hline$I$ & Indicator variable \\
\hline ZAI & Prey availability index \\
\hline $\mathrm{LZO}$ & Predator-prey overlap \\
\hline ZA & Amplitude of the prey cycle \\
\hline $\mathrm{ZM}$ & Magnitude of the prey cycle \\
\hline LZP & $\begin{array}{l}\text { Difference in peak timing of prey and } \\
\text { predator cycles }\end{array}$ \\
\hline LZI & $\begin{array}{l}\text { Difference in initiation timing of prey and } \\
\text { predator cycles }\end{array}$ \\
\hline LZG & $\begin{array}{l}\text { Difference in maximum growth rate (step } \\
\text { increase) of prey and predator cycles }\end{array}$ \\
\hline DOY & Day of year \\
\hline YEAR & Year \\
\hline LON & Longitude \\
\hline LAT & Latitude \\
\hline $\mathrm{ST}$ & Sea temperature \\
\hline $\mathrm{ST}_{\mathrm{A}}$ & Sea temperature anomaly \\
\hline$N_{\text {eggnet }}$ & Number of egg nets \\
\hline$N_{\text {ringtrawl }}$ & Number of ring trawls \\
\hline$A$ & Area under the curve \\
\hline$t$ & Time, in days \\
\hline $\mathrm{SD}$ & $\begin{array}{l}\text { Standard deviation of either prey or } \\
\text { predator }\end{array}$ \\
\hline$m$ & $\begin{array}{l}\text { Timing of peak abundance or biomass of } \\
\text { either prey or predator }\end{array}$ \\
\hline$A_{L}$ & Area under the predator curve \\
\hline$A_{Z}$ & Area under the prey curve \\
\hline LI & $\begin{array}{l}\text { Annual larval and post-larval abundance } \\
\text { index }\end{array}$ \\
\hline
\end{tabular}

and both L4 and L5 eat all stages (max. copepod length: $2.76 \mathrm{~mm}$ ).

\subsection{Temperature data}

We estimated sea temperature (ST; upper $50 \mathrm{~m}$ ) from the Nordic Seas $4 \mathrm{~km}$ numerical ocean model hindcast archive (SVIM) from 1959-1992 (Lien et al.
2013). We matched the SVIM data with the larvae and zooplankton collected by PINRO data by averaging the SVIM ST for the upper $50 \mathrm{~m}$ for each of the stations where PINRO data were collected (Fig. 1).

\subsection{Modelling}

The models on predator and prey were based on Stige et al. (2017) and Kvile et al. (2014), respectively. We used the data to develop a statistical model that quantified the spatio-temporal distribution of each stage and species as a function of temperature for each class (stage class for prey, size class for predator) from day of year (DOY) 107 ( 17 April) to 208 ( 27 July). DOY 107 and 208 were chosen based on data availability. However, the model outputs were only considered between DOY 120 (30 April) and 205 (24 July) because the models predicted unrealistic, negative abundance on the tails of the seasonal cycles. Model equations and scores can be found in Table S1. All statistics and plotting were performed in R v.3.6.2 (R Core Team 2019). Note that in this study we use lowercase $\mathrm{r}^{2}$ to represent goodness of fit of our models, instead of the commonly used $\mathrm{R}^{2}$, to avoid confusion with recruitment (here represented by $R$ ).

For the prey $C$. finmarchicus, we fitted a generalised additive model (R package 'mgcv' version 1.831; Wood 2017) for each copepod stage class, $i$ (nauplii, CI-CIII, CIV-CV, CVI M-F). This model was based on Kvile et al. (2014):

$$
\begin{aligned}
& \log \left(Z_{x t}+1\right)=\alpha+f_{1}\left(\mathrm{DOY}_{t}\right)+f_{2}\left(\mathrm{DOY}_{t}\right) \cdot \mathrm{ST}_{\mathrm{Axt}} \\
& +f_{3}\left(\mathrm{LON}_{x}, \mathrm{LAT}_{X}\right)+\mathrm{YEAR}_{t}+\varepsilon_{x t} \\
& \varepsilon_{x t} \sim N\left(0, \sigma_{x t}^{2}\right)
\end{aligned}
$$

Here, $Z_{x t}$ is copepod abundance of the given stage class at location $x$ and time $t$. The coefficient $\alpha$ is the intercept. The smooth function $f_{1}$ of DOY estimates the average seasonal change in abundance. The smooth function $f_{2}$ of DOY gives the DOY-dependent coefficient for the effect of sea temperature anomaly $\left(\mathrm{ST}_{\mathrm{A}}\right.$; calculated as in Kvile et al. 2014) and estimates how the seasonal pattern varies with ST. The 2-dimensional smooth function $f_{3}$ of longitude (LON) and latitude (LAT) estimates the time-averaged spatial

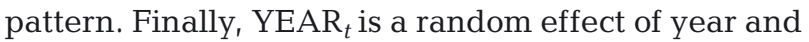
$\varepsilon_{x t}$ is a normally distributed error term. For the model to be identifiable, the functions $f_{1}$ and $f_{3}$ and terms $\mathrm{YEAR}_{t}$ and $\varepsilon_{x t}$ had means zero. The model results for each stage class abundance $\left(Z_{i}\right)$ were then multiplied by stage-specific weights of $C$. finmarchicus from Kanaeva (1962) to get $Z_{i}$ as biomass (in $\mathrm{mg} \mathrm{m}^{-3}$ ). 
For the predator G. morhua, we used the Tweedie family (since the data were zero-inflated; Dunn \& Smyth 2005, 2008, Dunn 2017) for each larval size class, $j$ (L2, L3, L4 and L5). This model was based on Stige et al. (2017):

$L_{x t}=\alpha+g_{1}\left(\mathrm{DOY}_{t}\right)+g_{2}\left(\mathrm{DOY}_{t}\right) \cdot \mathrm{ST}_{\mathrm{Axt}}+g_{3}\left(\mathrm{LON}_{x}, \mathrm{LAT}_{x}\right)$ $+\beta_{1} \cdot \log \left(N_{\text {eggnet, } x t}+1\right)+\beta_{2} \cdot \log \left(N_{\text {ringtrawl, } x t}+1\right)+\mathrm{YEAR}_{t}+\varepsilon_{x t}$

Here, $L_{x t}$ is cod larval abundance of a given size class at location $x$ and time $t$. The terms have similar interpretation as in Eq. (1), but were estimated separately from the ones in those models. The coefficients $\beta_{1}$ and $\beta_{2}$ account for sample size, with $N_{\text {eggnet }}$ being the number of egg net hauls and $N_{\text {ringtrawl }}$ the number of ring trawl hauls. We used different coefficients for the effects of egg nets and ring trawls because the capture efficiency is likely to differ between the 2 gears.

$Z_{i}$ and larval abundances by size class $\left(L_{j}\right)$ were predicted for each DOY, LON and LAT, but only for those locations that had at least $10 \%$ estimated probability of sampling cod larvae at each size class (Fig. S1, see also Section B in the Supplement).

The food available for each larval size class $L_{j}$ was calculated by adding the abundance or biomass of all stage classes of $C$. finmarchicus (i.e. $Z_{i}$ ) that a specific larval size class is able to eat (see Section 2.1). We calculated this new index of the larval prey availability $\left(\mathrm{ZAI}_{j}\right)$ as follows:

$$
\mathrm{ZAI}_{j}=\sum_{i=1}^{i=4} Z_{i} I_{i}
$$

Here, $I_{i}$ is an indicator variable, which is 1 if a copepod stage class is included in the diet of cod larval size class $i$, and 0 if not. Further details on the calculation of $\mathrm{ZAI}_{j}$ can be found in Section B of the Supplement.

Both $L_{j}$ and $\mathrm{ZAI}_{j}$ were integrated over space to compute a single value for each DOY and YEAR prior to the calculation of the phenology metrics.

\subsection{Phenology metrics}

The results from the previous section were used to estimate a total of 6 metrics for each larval size class $j$. A detailed description of each phenology metric is available in Table 2 . In short, 5 of these metrics are based on commonly used metrics from the literature (references in Table 2), whereas the sixth refined the metric of Durant et al. (2005) to take into account the spatial dimension.
The first 5 metrics are zooplankton amplitude (max. $Z \mathrm{AI}_{j}, \mathrm{ZA}_{j}$ ), zooplankton magnitude (sum total $\mathrm{ZAI}_{j}, \mathrm{ZM}_{j}$ ), peak timing (when either $\mathrm{ZAI}_{j}$ or $L_{j}$ reach their max., $\mathrm{LZP}_{j}$ ), timing of initiation (when either $\mathrm{ZAI}_{j}$ or $L_{j}$ surpass $5 \%$ of their annual median for at least 2 consecutive weeks, $\mathrm{LZI}_{j}$ ), maximum growth rate (max. daily increase in either $Z_{A A}$ or $L_{j}, L G_{j}$ ), and predator-prey overlap $\left(\mathrm{LZO}_{j}\right)$. $\mathrm{ZA}_{j}$ and $\mathrm{ZM}_{j}$ were estimated from $Z A_{j}$. The timing metrics $\left(\mathrm{LZI}_{j}, \mathrm{LZP}_{j}\right.$ and $\mathrm{LZG}_{j}$ ) were calculated for both $\mathrm{ZAI}_{j}$ and $L_{j}$ per larval size class $j$, and then the latter was subtracted from the former. Thus, a positive value indicates that the timing of prey occurred later than the timing of predator, whereas a negative value indicates it occurred earlier.

The sixth metric, $\mathrm{LZO}_{j}$ was calculated as described in Durant et al. (2005; their Fig. 1). The equations used in the calculation are available in Table 2 . In short, we calculated the area of overlap between the estimated curves describing the change of $L_{j}$ and $\mathrm{ZAI}_{j}$ over time, assuming that this area is proportional to the survival of young $\operatorname{cod}$ to $R$ at age 3 . We first calculated the area of the curve $\left(A_{j}\right)$ for each larval size class $j$ for both predator $\left(A_{L j}\right)$ and prey $\left(A_{Z j}\right)$, assuming that the seasonal trends in both $L_{j}$ and $\mathrm{ZAI}_{j}$ follow a Gaussian curve defined by the estimated standard deviation (SD) and the timing of the peak ( $m$; peak is defined as ZA) of $L_{j}$ and $\mathrm{ZAI}_{j}$. We then calculated the area of overlap by calculating the minimum of the integrals $A_{L j}$ and $A_{Z j}$, as shown in Table 2.

$L_{j}$ is in units of ind. $\mathrm{m}^{-3}$ and $\mathrm{ZAI}_{j}$ in $\mathrm{mg} \mathrm{m}^{-3}$ (or ind. $\mathrm{m}^{-3}$ when we used abundance), however, $\mathrm{LZO}_{j}$ has no units (as they cancel each other); therefore, we considered $\mathrm{LZO}_{j}$ a dimensionless metric. Further details on how to calculate $\mathrm{LZO}_{j}$ can be found in Durant et al. (2005) and in Table 2. Recently, Durant et al. (2019) published the $\mathrm{R}$ code to calculate the overlap.

All metrics were computed annually for 1959-1992 for each larval size class $j$. Each of the 6 metrics was then tested for its ability to explain variability in $R$ for each larval size class $j$ with a 3 yr lag (G. morhua recruits at age 3) as follows:

$$
\begin{aligned}
& R_{t}=a+b \cdot M_{t-3}+\varepsilon_{t} \\
& \varepsilon_{t} \sim N\left(0, \sigma^{2}\right)
\end{aligned}
$$

Here, $R_{t}$ is recruitment in year $t, a$ and $b$ are the intercept and the slope, respectively, of the regression line, $M$ is a given metric for a given larval size class $\left(\mathrm{ZA}_{j}, \mathrm{ZM}_{j}, \mathrm{LZP}_{j}, \mathrm{LZI}_{j}, \mathrm{LZG}_{\mathrm{j}}\right.$ or $\left.\mathrm{LZO}_{j}\right)$, and $\varepsilon_{t}$ is a size-class-specific normally distributed error. Estimates of $R$ were based on the most recent stock assessment ICES (2018). We also tested the effect of 
Table 2. Description of the phenology metrics used: amplitude, magnitude, peak timing, timing of initiation, timing of maximum growth and predator-prey overlap. Orange star $(\star)$ indicates the output estimated by each metric, which is a time series from 1959-1992 per larval size class $(j) .(\sim)$ median; see Table 1 for acronym descriptions

\begin{tabular}{|c|c|c|c|c|}
\hline Metric & Description (reference) & Input & Equation & Scheme \\
\hline $\begin{array}{l}\text { ZA: prey } \\
\text { amplitude }\end{array}$ & $\begin{array}{l}\text { Amplitude of the prey cycle: } \\
\text { peak value, i.e. highest } \\
\text { production (e.g. Yoder \& } \\
\text { Kennelly 2003) }\end{array}$ & ZAI & $\mathrm{ZA}=\operatorname{maxZAI}$ & \\
\hline $\begin{array}{l}\text { ZM: prey } \\
\text { magnitude }\end{array}$ & $\begin{array}{l}\text { Magnitude of the prey cycle: } \\
\text { total seasonal production (e.g. } \\
\text { Platt \& Sathyendranath 2008) }\end{array}$ & ZAI & $\mathrm{ZM}=\sum_{\mathrm{DOY}=107}^{\mathrm{DOY}=208} \mathrm{ZAI}$ & \\
\hline $\begin{array}{l}\text { LZP: peak } \\
\text { timing }\end{array}$ & $\begin{array}{l}\text { Difference in peak timing of } \\
\text { prey and predator cycles: day of } \\
\text { the highest production (e.g. } \\
\text { Platt et al. 2003) }\end{array}$ & $L, \mathrm{ZAI}$ & $\mathrm{LZP}=\mathrm{DOY}_{\operatorname{maxZAI}}-\mathrm{DOY}_{\max L}$ & \\
\hline $\begin{array}{l}\text { LZI: } \\
\text { initiation } \\
\text { timing }\end{array}$ & $\begin{array}{l}\text { Difference in initiation timing of } \\
\text { prey and predator cycles: } \\
\text { initiation timing is defined as } \\
\text { the day when the productions } \\
\text { rises } 5 \% \text { above the median } \\
(\text { Siegel et al. 2002) })^{\mathrm{a}}\end{array}$ & $L, \mathrm{ZAI}$ & $\mathrm{LZI}=\mathrm{DOY}_{\mathrm{ZAI}>1.05 \cdot \widetilde{\mathrm{ZAI}}}-\mathrm{DOY}_{\mathrm{L}>1.05 \cdot \widetilde{\mathrm{L}}}$ & \\
\hline $\begin{array}{l}\text { LZG: } \\
\text { maximum } \\
\text { growth } \\
\text { timing }\end{array}$ & $\begin{array}{l}\text { Difference in timing of maxi- } \\
\text { mum growth of prey and } \\
\text { predator cycles: timing of maxi- } \\
\text { mum growth is defined as the } \\
\text { day of the highest step increase } \\
\text { (e.g. Rolinski et al. 2007) }\end{array}$ & $L$, ZAI & $\begin{aligned} \mathrm{LZG}= & \mathrm{DOY}_{\max \left(\mathrm{ZAI}_{\mathrm{DOY}+1}-\mathrm{ZAI}_{\mathrm{DOY})}\right.}- \\
& \mathrm{DOY}_{\max \left(\mathrm{L}_{\mathrm{DOY}+1}-\mathrm{L}_{\mathrm{DOY}}\right)}\end{aligned}$ & \\
\hline $\begin{array}{l}\text { LZO: } \\
\text { predator- } \\
\text { prey } \\
\text { overlap }\end{array}$ & $\begin{array}{l}\text { Area in which } A \text { for the prey } \\
\text { overlaps with that of the } \\
\text { predator: the area under both } \\
\text { curves (orange area, Durant et } \\
\text { al. 2005, 2019) }\end{array}$ & $L$, ZAI & $\begin{array}{l}A=\frac{1}{\sqrt{2 \pi} \cdot \mathrm{SD}} \cdot \mathrm{e}\left[\frac{-(t-m)^{2}}{2 \mathrm{SD}^{2}}\right] \\
\mathrm{LZO}=\int_{\mathrm{DOY}=107}^{\mathrm{DOY}=208} \min \left(A_{L}, A_{Z}\right) d m\end{array}$ & \\
\hline
\end{tabular}

larval abundance on $R$ by adding an annual larval and post-larval abundance index in June-July (LI; taken from Stige et al. 2015) to the model represented by Eq. (4) without any metric (so it reads as $R=a+b \times \mathrm{LI}+\varepsilon$ ), and with 5 of the metrics used in this study $\left(Z_{j}, Z_{j}, L_{j}, \mathrm{LZI}_{j}\right.$ and $\left.\mathrm{LZG}_{j}\right)$, but not for $\mathrm{LZO}_{j}$ because this metric already accounts for larval abundance (Table 2). We tested the residuals from each of the linear regressions for temporal autocorrelation, but no significant autocorrelation existed.

\section{RESULTS}

\subsection{Seasonal trends}

We show the estimated seasonal trends in $L_{j}$ and $Z_{i}$ for a selected year (1970) as an example (Fig. 2), which was a year associated with a high $R$ index. Results for a year with low $R$ (1979) are shown in Fig. S3.

Predictions of $L_{j}$ showed an expected succession of $j$, with L2 having a peak around 1 June, L3 in mid- 

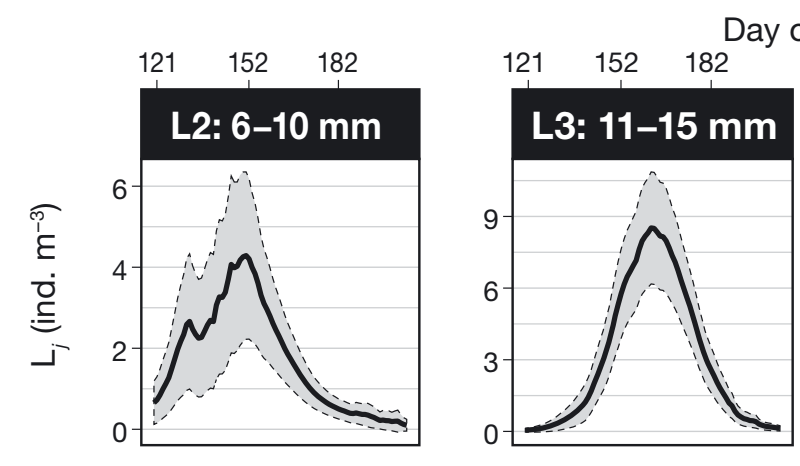

Day of year
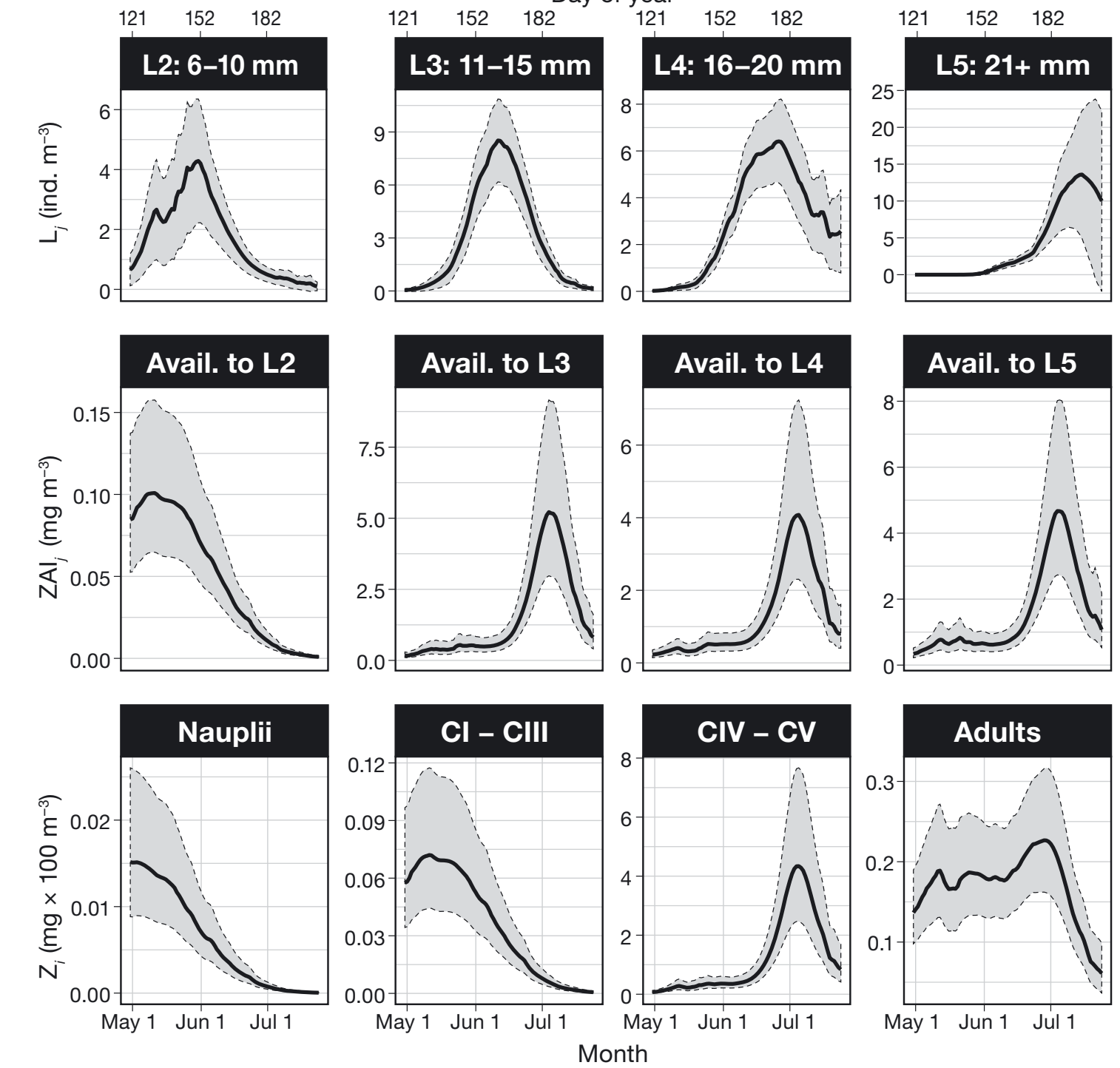

Fig. 2. Predictions of Gadus morhua larval abundance ( $L_{j}$, top), prey (Calanus finmarchicus) availability index (ZAI ${ }_{j}$ middle) per larval size class $(j)$, and $C$. finmarchicus biomass $\left(Z_{i}\right.$, bottom) per $C$. finmarchicus stage class (i) for 1970 . Shaded areas: $95 \%$ confidence intervals. Avail.: available. Note that the $y$-axis varies per panel, as the seasonality would have been masked otherwise

June, L4 at the end of June and L5 in mid-July (Fig. 2 top). The highest average abundance was found for L5. Similar results were found for all years (for instance, see results for year 1979 in Fig. S3).

Predictions of $Z_{i}$ showed an expected succession of $i$ from nauplii to $\mathrm{CIV}-\mathrm{CV}$, whereas the adult stage classes seemed to be present throughout the sampling period (Fig. 2 bottom). The lowest average biomass was found for the nauplii stage classes and the highest for stage classes CIV-CV. Similar results were found for all years (for instance, see results for year 1979 in Fig. S3).
Again, results are shown for 1970 only (Fig. 2 middle, but results for year 1979 can be found in Fig. S3). Because Gadus morhua size class L2 only eats Calanus finmarchicus nauplii and CI-CIII stage classes, the biomass of $C$. finmarchicus available for L2 was the lowest of the 4 size classes, which was evident in $\mathrm{ZAI}_{j}$ (Figs. 2 [middle], S3, S4, \& S5). The difference in the shapes of the 4 curves is because the location of sampling for each predator size class is taken into account (Fig. S1). Data used for calculation of these curves is available in the Supplement. 


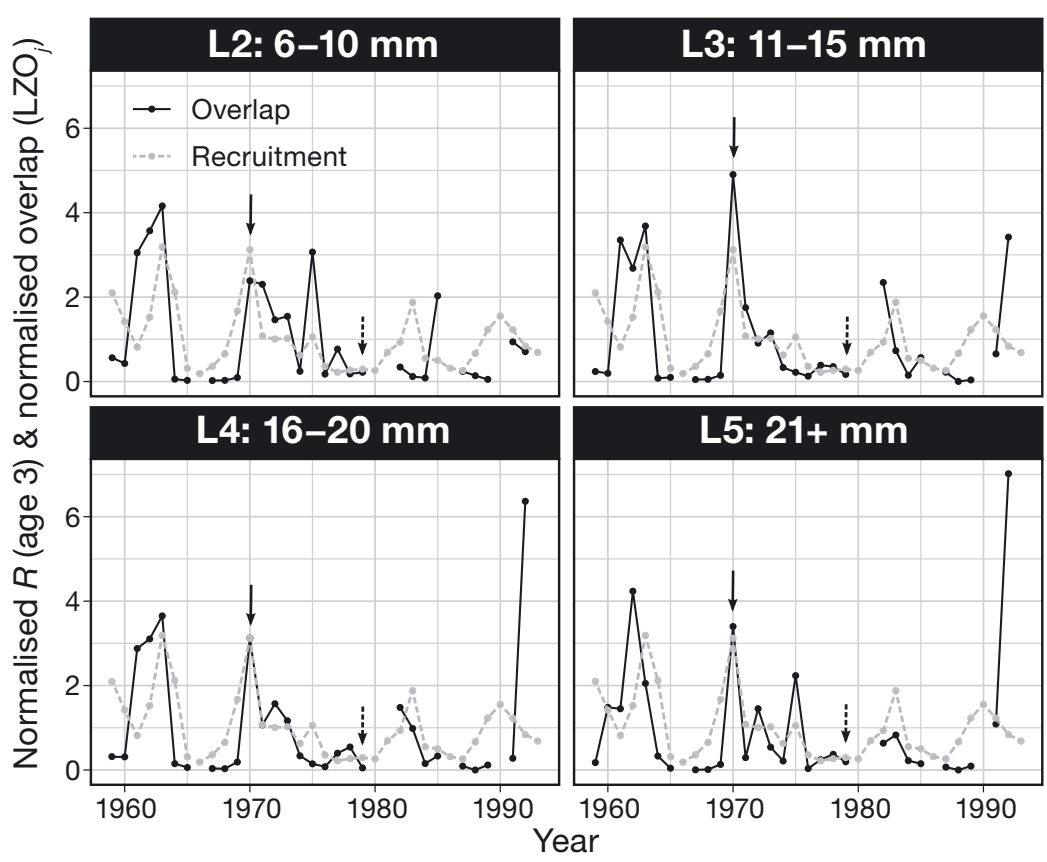

Fig. 3. Time series of the predator-prey overlap $\left(\mathrm{LZO}_{j}\right)$ and recruitment $(R)$. L2-L5: Gadus morhua larval length classes. The $R$ time series has been lagged 3 yr to the spawning year. For plotting and comparison purposes, both $\mathrm{LZO}_{j}$ and $R$ have been normalised (divided by the mean). Full arrow points to year 1970; dashed arrow points to 1979. Note that the $y$-axis is kept constant for all panels creased (leading to a biomass between 6.50 and $24.74 \mathrm{mg}$ predator ${ }^{-1}$ ), which led to a very high overlap for larvae larger than $16 \mathrm{~mm}$ (lower panels in Fig. 3).

We compared the relationship between $R$ and the other phenology metrics calculated based on either prey abundance or biomass (Fig. 4; time series of all combinations can be seen for both biomass in Fig. S6 and abundance in Fig. S7). None of the metrics showed a positive and significant correlation with $R$, except for $\mathrm{LZO}_{j}\left(\mathrm{r}^{2}=\right.$ 0.29 , p < 0.005; Figs. 4 \& S8). In addition, the interannual variability of the timing metrics $\mathrm{LZI}_{j}, \mathrm{LZP}_{j}$ and $\mathrm{LZG}_{j}$ differed among size classes (Fig. S6). LZI $\mathrm{I}_{j}$ was mostly negative and close to 0 for the first-feeders (L2), meaning that the timing of initiation of both prey and predator (i.e. LZI $_{j}$ ) occurred simultaneously for most years. $\mathrm{LZI}_{j}$ of $\mathrm{L} 3$ and L4 occurred earlier than that of the prey (Fig. 2). L5 larvae showed a more

\subsection{Interannual variability}

The relationship between the degree of $\mathrm{LZO}_{j}$ and $R$ (with a 3 yr lag) was positive for all size classes; however, the relationship was not statistically significant for L5 (see Fig. 4). These results suggested that a high overlap was linked to a high $R$, and this was visible when comparing extreme years: a year with a high index (1970) to a year with a low one (1979; Fig. 3). To better understand the differences between 1970,1979 , and the general time series, we calculated the number of prey items per individual predator, as well as the prey biomass per individual predator (Fig. S5). For the 1970 year-class, $R$ at age 3 (3 yr later) was strong and linked to a high overlap, indicating that food was not a limiting factor. However, the biomass (and abundance) of C. finmarchicus per predator was at least 3 orders of magnitude higher in 1979 (97.49-11 465.22 mg per 3563-34 282 ind.) than in 1970 (2.87-50.29 mg per 125-180 ind.) (Fig. S5). Therefore, even though food was not limiting, and even though the larvae were at the right place at the right time, the degree of $\mathrm{LZO}_{j}$ was still very low (due to low larval abundance; Fig. S3). In 1992, however, the number of prey (and also their biomass) per predator decreased, but the number of predators in-

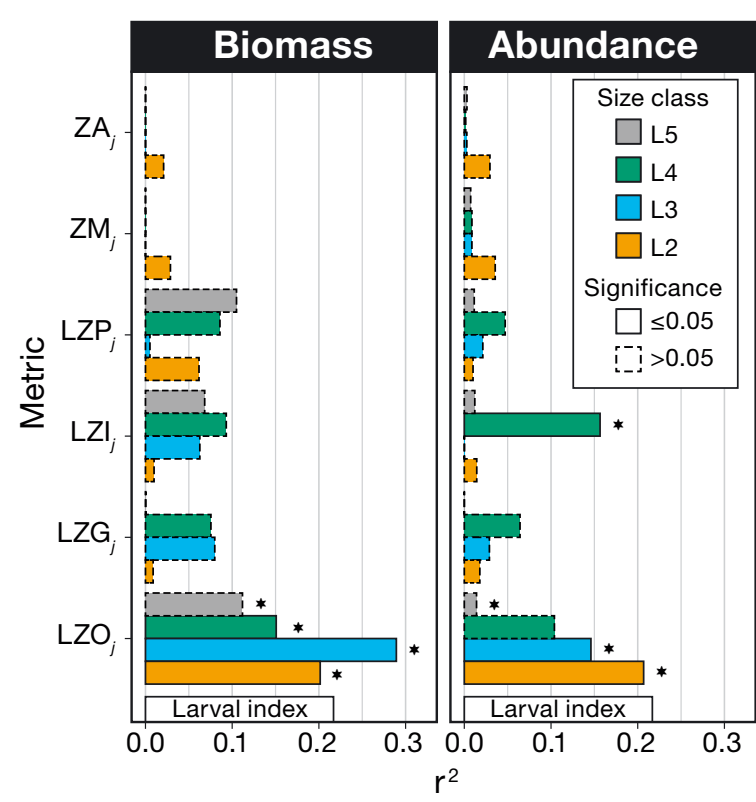

Fig. 4. Values of $\mathrm{r}^{2}$ for the relationships between Gadus morhua recruitment $(R)$ and each of the metrics used in this study for both biomass and abundance (left and right, respectively). The $\mathrm{r}^{2}$ on larval index (white bar) refers to the lineal regression between the annual larval abundance index (not stage specific) and $R_{i}\left({ }^{*}\right)$ indicate which metric had the lowest value of Akaike's information criterion per larval size class. See Table 1 for metric descriptions 
diverse range of positive and negative values. In general, this metric had a mean of $7.09 \pm 14.1 \mathrm{~d}$. LZP $_{j}$ varied slightly more between earlier and later prey availability between $1.76 \pm 16.9 \mathrm{~d}$, whereas $\mathrm{LZG}_{j}$ varied in the range of $7.38 \pm 25.7$. The relatively high values in the timing metrics are because, in some years and size classes, we observed that $C$. finmarchicus had a double peak, so the metrics calculated on their seasonal cycle relate to the first peak. If the larval abundance in those same size classes and years initiates and peaks much later, the discrepancy between prey and predator timings will be higher. $\mathrm{ZA}_{j}$ and $\mathrm{ZM}_{j}$ varied in different order of magnitudes with means of $958 \pm 1487$ and $28056 \pm 42044 \mathrm{mg} \mathrm{m}^{-3}$, respectively. $\mathrm{LZO}_{j}$ had a mean of $60.5 \pm 94.7$.

The estimated effect of LI on $R$ was significant $\left(\mathrm{r}^{2}=\right.$ $0.22, \mathrm{p}<0.05)$. When adding LI to Eq. (4), the performance of each metric changed (see Fig. S9). In some cases, $\mathrm{r}^{2}$ increased when LI was added. For example, LZP ${ }_{j}$, particularly for prey of L5 larvae, contributed most to explaining variation in $R$ when LI was accounted for. However, $\mathrm{LZO}_{j}$ for L3 larvae explained more of the variation in $R$ than any other of the combination of larval and prey indices.

In addition, we tested how sensitive the relationship between $R$ and $\mathrm{LZO}_{j}$ was to the scaling of the predator-prey abundance (Fig. S10). We observed that, for instance, even though the relationship between $\mathrm{LZO}_{j}$ for $j=5$ and $R$ was not significant on a 1:1 scaling ratio (Fig. 4), there was a wide range of other scaling factors where the relationship for L5 was significant for both abundance and biomass (see green areas in Fig. S11 bottom).

\section{DISCUSSION}

This study's main objective was to assess the effect of the predator-prey co-occurrence on predator recruitment in the Norwegian-Barents Sea system to better explain whether MMH dynamics are present in the region. We did this by focusing on the larvae of Gadus morhua (Northeast Arctic cod) as a predator and the copepod Calanus finmarchicus as their main prey (Ellertsen et al. 1987, Vikebø et al. 2007). We quantified the spatio-temporal overlap through time from 1959-1992 and compared that with $\operatorname{cod} R$ (when they enter the fisheries at $3 \mathrm{yr}$ of age). We found that $R$ of the Northeast Arctic cod is indeed positively and significantly correlated with the spatio-temporal overlap between cod larvae of all size classes (except $21+\mathrm{mm}$ ) and their prey. The results of this analysis thus act as proof of concept and as a step to develop- ing novel statistical methods to identify robust phenology metrics that consider space and describe the overlap in any trophic coupling.

Even though MMH explained a significant part of the observed $R$, we were limited in our study by the fact that $R$ is first measured $3 \mathrm{yr}$ after larval firstfeeding, and there are many factors that affect fish survival during their first years. Given the data we had access to, there were essentially 2 ways to test the effects of $\mathrm{MMH}$ on $R$ : by using an integrative metric, such as $\mathrm{LZO}_{j i}$ or by adding LI as a covariate in models of $\operatorname{cod} R$. The first approach accounts for both predator and prey, and proved to be successful in explaining up to $29 \%$ of the variation in $R$ (Fig. 4). The results of the second approach were, however, inconclusive, as most metrics had similar $\mathrm{r}^{2}$ to one another (Fig. S9), indicating that a large part of the predictive power of our overlap metric comes from understanding the number of available larvae. Alternatively, other factors may play a big role, such as spatial distribution of both prey and predator or copepod abundance/biomass.

The $\mathrm{LZO}_{j}$ metric was also tested for different scaling factors, to show how sensitive this type of metric (integrative) is. In theory, changing the scaling of one compared to the other will affect the correlation between the $\mathrm{LZO}_{j}$ and $R$. We tested the sensitivity of the $\mathrm{LZO}_{j}$ metric to such a scaling change (Fig. S10). While some scaling factors provided higher $\mathrm{r}^{2}$, we did not use them since they implied using a different scaling factor per predator size class, which would not be meaningful since they were all collected in the same sampling haul. However, changing the biomass (or abundance) of zooplankton makes sense because each individual prey item has a different impact on an individual predator larvae depending on the larval size class. For instance, nauplii will meet the requirements of a L2 larva sooner than those of a larger L5 larva, simply because the food requirements of a L5 larva are higher than those of a L2 larvae. Because we had no access to information on larval stomach fullness, we did not use any scaling factors.

Most studies looking into the MMH focus on using a suit of phenology metrics that describe either the timing or magnitude of specific biological events (see examples in Ferreira et al. 2014). However, such metrics fail to assess the interaction between prey and predator in space, time and magnitude. Thus, relevant information may be limited by the choice of metrics. In our study, the variability in LZO of L3 larvae explained $29 \%$ of the variability in $R$, meaning that what happens within those weeks of life influences the abundance of age $3 \mathrm{cod}$, even though it is not the 
only process involved that will affect survival up to $3 \mathrm{yr}$ of age. In detail, $\mathrm{LZO}_{j}$ was high in 1970, which was also a year that resulted in a high $R$. In that year, each G. morhua larvae had between 2.87 and $50.29 \mathrm{mg} \mathrm{m}^{-3}$ of C. finmarchicus available (Fig. S5). However, even though prey available to each individual larva in 1979 was at least 3 orders of magnitude higher than in 1970, LZO was low in 1979, as was the resulting $R 3 \mathrm{yr}$ later. In short, even though there was plenty of available food at the time and place for the larvae to consume, there may have been too few larvae to produce a strong year-class (Fig. 3). The amount of larvae may thus not have been sufficient to allow the cohort to persist up to age 3 at a high enough level to lead to high $R$. A potential explanation for this (and one we did not test in this study) may be a strong Allee effect (i.e. a positive density-dependence effect), in which the growth rate of the first-feeding larvae was lowered in response to low densities (Shepherd \& Cushing 1980), which would explain the low overlap and subsequent low $R$ in years with more than enough available food. By adding LI to Eq. (4) (also see Figs. 4 \& S9), we thus show that larval abundance does play an important role in explaining $R$. However, another potential explanation for the low $R$ in 1979 may be higher mortality after the larval stages, a hypothesis that we cannot assess with the models used here.

Some unexpected results were found in our analyses. For instance, in 1992, a year with the highest LZO for larvae larger than $16 \mathrm{~mm}$ (lower panels in Fig. 3), the available biomass of prey per larva was similar to 1970 (Fig. S5), but $R$ was much lower than in 1970. For 1992, our metric does not follow the same pattern at explaining cod $R$. The overlap in 1992 shows that our metric also takes into account how the predator and prey densities interact with each other, i.e. the area of the $Z$ curve covered by the $L$ curve was actually much larger than in any other year because in 1992, compared to the other years, prey densities were some of the lowest, whereas the predator densities were relatively high. Nevertheless, these results also suggest that our overlap metric does not take into account how many (or how much) prey each individual predator needs or even ingests. Ellertsen et al. (1987) suggested that, in order for a successful first-feeding to occur, there must be $5-10$ ind. prey $\mathrm{l}^{-1}$. They also suggested a feeding ratio (number of prey organisms per larval gut) between 0.6 and 4.3 from 1976-1984. In our analyses, our lowest ratio of available C. finmarchicus per individual G. morhua larvae was around 8751 ind. $\mathrm{m}^{-3}$ (around 8.75 ind. $\mathrm{l}^{-1}$; Fig. S5), thus indicating that food limitation was not an issue. However, some of the years in which this ratio was the lowest - but still above Ellertsen et al. (1987)'s threshold (marked by the dashed, dark grey line in Fig. S5) - corresponded to years with a high $R$ (e.g. 1963 or 1970). This may have been because of a higher number of successful prey encounters and/or other factors other than food determining high survival in those years.

\subsection{Novelties of the MMH overlap metric}

This study focused on acknowledging the importance of the following critical components: fish larval abundance, zooplankton biomass, time, space and mismatch. This is because first, some of the most influential MMH studies (Platt et al. 2003, Durant et al. 2007, Koeller et al. 2009) focused on linking phytoplankton to fish. However, most larval fish begin feeding on early-stage zooplankton rather than phytoplankton (Beaugrand et al. 2003, Neuheimer et al. 2018). Here, we used size-class-specific prey size to represent the real-life diet of cod larvae in the Norwegian-Barents Sea system. These larvae feed mainly on C. finmarchicus (Ellertsen et al. 1987, Brander 1994, Vikebø et al. 2007) of different sizes, which is limited by the gape size of larval cod. We found no evidence in the literature of a size-class-specific overlap being used to compare to $R$, so our study improves our understanding of the cod-copepod coupling in the Norwegian-Barents Sea system. However, the data set used in this study probably undersampled nauplii and smaller copepodites that may have passed through the mesh (as suggested by Stige et al. 2014), which could have impacted the results.

Second, a successful MMH study considers both the timing and location of biological events (Carroll et al. 2019). In our study, we took into consideration the spatial distribution of both prey and predator and only estimated the overlap metric when both cooccurred, as opposed to taking an overall temporal average for the entire region.

Third, as opposed to previous MMH studies (Cushing 1990, Edwards \& Richardson 2004), our metric does not assume a constant timing of larvae; i.e. the timing of larval occurrence (either peak or initiation) varies in our study. While the former can be assumed to be true for some stocks since the variation in spawning time is relatively small (Cushing 1969), this approximation is not appropriate when spawning is considered at several locations, as we did in this study. Cod are known to be batch spawners, and the spawning period lasts for 2-2.5 mo (Kjesbu 1989). 
Furthermore, temperature-dependent development of eggs and larvae may cause variation in larval timing (e.g. Kristiansen et al. 2011).

Fourth, the degree to which predator and prey cooccur is relevant, as it allows for a more detailed understanding of how the predator-prey coupling varies over time. Therefore, it is important that one assesses both the seasonal cycles, but also the overall strength (magnitude and amplitude) of each predator-prey pair beforehand. Our study not only acknowledged the timing and location, but it also took into account the abundance (or biomass) of both predator and prey, as this can mitigate potential mismatches (Durant et al. 2005).

While the Northeast Arctic cod is a very important species within the Norwegian-Barents Sea ecosystem, C. finmarchicus is even more so (Brander 1994). Our results on the $C$. finmarchicus seasonal cycle are consistent with those of Kvile et al. (2014) (even though we used the same data set, we only focused on the upper $50 \mathrm{~m}$; our model also slightly differs from theirs), with indications of a peak of abundance and biomass in spring for both nauplii and stage classes CI-CIII, whereas stage classes CIV to adults peaked towards the summer (Figs. 2 \& S3). Varpe \& Fiksen (2010) also reported peaks of abundance and biomass in June/July for C. finmarchicus stage classes CV to adults (see their Fig. 2), which match our findings.

Northeast Arctic cod spawn between mid-February and early May, with a mean around the last days of March and the first of April (Ellertsen et al. 1987, Brander 1994, Langangen et al. 2016). The eggs then hatch in late April, and the cod larvae start feeding mainly on C. finmarchicus nauplii on Days 5-8 posthatching (at $5^{\circ} \mathrm{C}$, according to Ellertsen et al. 1987 and Brander 1994). Our results suggest that the timing of the first-feeders (i.e. L2) peaked from mid to late May in 1983 (a warm year, see Fig. S11), whereas Ellertsen et al. (1987) suggested a peak in late April. These authors also reported the curve for the first-feeders of 1981 (a cold year), a year for which we unfortunately did not have data. Having no data for 1981, we used another cold year (1979; see Kvile et al. 2014) for comparison. In our results, we observed a peak of abundance and biomass for the first-feeders around 1 June in 1979, whereas Ellertsen et al. (1987) observed it around 17 May in 1981. The difference of $2 \mathrm{wk}$ between our results and those of Ellertsen et al. (1987) is constant for both warm and cold years, which leads us to believe that it is probably due to differences in sampling and/or modelling approaches.

\subsection{Conclusions}

Even though the overlap metric used in this study helps assess predator-prey MMH dynamics, we are aware that it requires spatio-temporal-rich data sets - which are rare. For this study, we had access to a spatially and temporally rich data set, which allowed us to pursue this route of analyses. However, in cases with poorly resolved data, careful consideration of all relevant players and all their counterparts is key. Nevertheless, a predator-prey overlap metric proves to be useful when data are available.

The survival of cod eggs from spawning to hatching $(10 \%)$, and larvae from hatching to first-feeding $(2-3 \%)$ is very low (Ellertsen et al. 1989), with an average of $0.00065 \%$ of the total egg production surviving to the age at $R$ (Kraus 2002, Bogstad et al. 2016). There is high mortality during the first weeks and months of a cod's life cycle. We used the information previously published on these species (G. morhua and C. finmarchicus) and this topic (MMH) to build a robust metric of predator-prey overlap. The long-term effect of low food availability is not as easy to measure (and/or test) as the effect of a fatal encounter with a successful predator. Even though our metric failed to account for sources of variability in the period between larval stages and $R 3 \mathrm{yr}$ later, which may play stronger roles than the MMH dynamics, our study adds to the understanding of how the amount of food available during the critical period affects survival in later stages.

Data availability. The data output of the predator-prey overlap $\left(\mathrm{LZO}_{j}\right)$ and all the other metrics $\left(\mathrm{ZA}_{j}, \mathrm{ZM}_{j}, \mathrm{LZP}_{j}, \mathrm{LZI}_{j}\right.$ and $\mathrm{LZG}_{j}$ ) per larval size class can be found at www.asofiaaferreira.com/spitfire/data.

Acknowledgements. A.S.A.F.'s SPITFIRE project was funded by the European Union's Horizon 2020 research and innovation programme under the Marie Skłodowska-Curie grant agreement No. 794301. L.C.S. and J.M.D. thank the Research Council of Norway (RCN grant No. 280468) for support. This work was completed during an AIAS-COFUND Fellowship to A.B.N. at the Aarhus Institute of Advanced Studies, which receives funding from the Aarhus University Research Foundation (Aarhus Universitets Forskningsfond) and the European Union's Seventh Framework Programme, Marie-Curie Actions (grant agreement 609033). The results of this publication reflect only the authors' view, and the Commission is not responsible for any use that may be made of the information it contains.

\section{LITERATURE CITED}

Beaugrand G, Brander KM, Lindley JA, Souissi S, Reid PC (2003) Plankton effect on cod recruitment in the North 
Sea. Nature 426:661-664

Bjørke H, Sundby S (1984) Distribution and abundance of post larval Northeast Arctic cod and haddock. In: OR Godø, S Tilseth (eds) The proceedings of the SovietNorwegian Symposium. Institute of Marine Research, Leningrad, p 72-98

Bogstad B, Yaragina NA, Nash RDM (2016) The early lifehistory dynamics of Northeast Arctic cod: levels of natural mortality and abundance during the first 3 years of life. Can J Fish Aquat Sci 73:246-256

Brander KM (1994) Spawning and life history information for North Atlantic cod stocks. ICES Coop Res Rep No. 205. International Council for the Exploration of the Sea, Copenhagen

Brander K, Mohn R (2004) Effect of the North Atlantic Oscillation on recruitment of Atlantic cod (Gadus morhua). Can J Fish Aquat Sci 61:1558-1564

* Campbell RG, Wagner MM, Teegarden GJ, Boudreau CA, Durbin EG (2001) Growth and development rates of the copepod Calanus finmarchicus reared in the laboratory. Mar Ecol Prog Ser 221:161-183

* Carroll G, Holsman KK, Brodie S, Thorson JT and others (2019) A review of methods for quantifying spatial predator-prey overlap. Glob Ecol Biogeogr 28:1561-1577

Cole H, Henson S, Martin A, Yool A (2012) Mind the gap: the impact of missing data on the calculation of phytoplankton phenology metrics. J Geophys Res 117:C08030

Cole HS, Henson S, Martin AP, Yool A (2015) Basin-wide mechanisms for spring bloom initiation: How typical is the North Atlantic? ICES J Mar Sci 72:2029-2040

Cushing DH (1967) The grouping of herring populations. J Mar Biol Assoc UK 47:193-208

* Cushing DH (1969) The regulatory of the spawning season of some fishes. ICES J Mar Sci 33:81-92

* Cushing DH (1990) Plankton production and year-class strength in fish populations: an update of the match/mismatch hypothesis. Adv Mar Biol 26:249-293

Dunn PK (2017) tweedie: evaluation of Tweedie exponential family models. R package version 2.3.0. https://cran.rproject.org/web/packages/tweedie

* Dunn PK, Smyth GK (2005) Series evaluation of Tweedie exponential dispersion model densities. Stat Comput 15: 267-280

Dunn PK, Smyth GK (2008) Evaluation of Tweedie exponential dispersion model densities by Fourier inversion. Stat Comput 18:73-86

₹ Durant JM, Hjermann DØ, Anker-Nilssen T, Beaugrand G, Mysterud A, Pettorelli N, Stenseth NC (2005) Timing and abundance as key mechanisms affecting trophic interactions in variable environments. Ecol Lett 8:952-958

* Durant JM, Hjermann DØ, Ottersen G, Stenseth NC (2007) Climate and the match or mismatch between predator requirements and resource availability. Clim Res 33: 271-283

* Durant JM, Hjermann DØ, Falkenhaug T, Gifford DJ and others (2013) Extension of the match-mismatch hypothesis to predator-controlled systems. Mar Ecol Prog Ser 474:43-52

Durant JM, Molinero JC, Ottersen G, Reygondeau G, Stige LC, Langangen $\varnothing$ (2019) Contrasting effects of rising temperatures on trophic interactions in marine ecosystems. Sci Rep 9:15213

Edwards M, Richardson AJ (2004) Impact of climate change on marine pelagic phenology and trophic mismatch. Nature 430:881-884
Eiane K, Tande KS (2009) Meso and macrozooplankton. In: E Sakshaug, GH Johnsen, KM Kovacs (eds) Ecosystem Barents Sea. Tapir Academic Press, Trondheim, p 209-234

Ellertsen B, Fossum P, Solemdal P, Sundby S, Tilseth S (1987) The effect of biological and physical factors on the survival of Arcto-Norwegian cod and the influence on recruitment variability. In: Loeng $\mathrm{H}$ (ed) Proc third Soviet-Norwegian Symp, 26-28 May 1986, Murmansk. Institute of Marine Research, Arendal, p 101-126

Ellertsen B, Fossum P, Solemdal P, Sundby S (1989) Relation between temperature and survival of eggs and first feeding larvae of the north-east Arctic cod (Gadus morhua). Rapp P-V Reun Cons Int Explor Mer 191:209-219

Ferreira AS, Visser AW, MacKenzie BR, Payne MR (2014) Accuracy and precision in the calculation of phenology metrics. J Geophys Res Oceans 119:8438-8453

*Fortier L, Ponton D, Gilbert M (1995) The match/mismatch hypothesis and the feeding success of fish larvae in icecovered southeastern Hudson Bay. Mar Ecol Prog Ser 120:11-27

Helle K (1994) Distribution of early juvenile Arcto-Norwegian cod (Gadus morhua L.) in relation to food abundance and watermass properties. ICES J Mar Sci 198:440-448

*Helle K (2000) Distribution of the copepodite stages of Calanus finmarchicus from Lofoten to the Barents Sea in July 1989. ICES J Mar Sci 57:1636-1644

Helle K, Pennington M (1999) The relation of the spatial distribution of early juvenile cod (Gadus morhua L.) in the Barents Sea to zooplankton density and water flux during the period 1978-1984. ICES J Mar Sci 56:15-27

Hjort J (1914) Fluctuations in the great fisheries of northern Europe viewed in the light of biological research. Rapp P-V Reun Cons Int Explor Mer 20:1-228

* Houde ED (2008) Emerging from Hjort's shadow. J Northwest Atl Fish Sci 41:53-70

ICES (2018) Report of the Arctic Fisheries Working Group. ICES CM 2018/ACOM:06

Ji R, Edwards M, Mackas DL, Runge JA, Thomas AC (2010) Marine plankton phenology and life history in a changing climate: current research and future directions. J Plankton Res 32:1355-1368

Kanaeva I (1962) Mean weight of copepods of central and northern Atlantic, the Norwegian and Greenland Seas. M Pishchepromizdat 46:253-266 (in Russian)

*Kjesbu OS (1989) The spawning activity of cod, Gadus morhua L. J Fish Biol 34:195-206

Kjesbu OS, Solemdal P, Bratland P, Fonn M (1996) Variation in annual egg production in individual captive Atlantic cod (Gadus morhua). Can J Fish Aquat Sci 53:610-620

*Koeller P, Fuentes-Yaco C, Platt T, Sathyendranath S and others (2009) Basin-scale coherence in phenology of shrimps and phytoplankton in the North Atlantic ocean. Science 324:791-793

Kraus G (2002) Variability in egg production of cod (Gadus morhua callarias L.) in the central Baltic Sea. PhD thesis, University of Kiel

Kristiansen T, Drinkwater KF, Lough RG, Sundby S (2011) Recruitment variability in North Atlantic cod and matchmismatch dynamics. PLOS ONE 6:e17456

Kvile K, Dalpadado P, Orlova E, Stenseth NC, Stige LC (2014) Temperature effects on Calanus finmarchicus vary in space, time and between developmental stages. Mar Ecol Prog Ser 517:85-104

* Langangen Ø, Ottersen G, Ciannelli L, Vikebø FB, Stige LC (2016) Reproductive strategy of a migratory fish stock: 
implications of spatial variations in natural mortality. Can J Fish Aquat Sci 73:1742-1749

Leggett WC, Deblois E (1994) Recruitment in marine fishes: Is it regulated by starvation and predation in the egg and larval stages? Neth J Sea Res 32:119-134

Lien VS, Gusdal Y, Albretsen J, Melsom A, Vikebø FB (2013) Evaluation of a Nordic Seas $4 \mathrm{~km}$ numerical ocean model hindcast archive (SVIM), 1960-2011. Fisken og havet 72013. Technical report, Institute of Marine Research, Bergen

Marshall CT, Kjesbu OS, Yaragina NA, Solemdal P, Ulltang $\varnothing$ (1998) Is spawner biomass a sensitive measure of the reproductive and recruitment potential of Northeast Arctic cod? Can J Fish Aquat Sci 55:1766-1783

Melle W, Ellertsen B, Skjoldal H (2004) Zooplankton: the link to higher trophic levels. Tapir Academic Press, Trondheim, p 137-202

Mukhina NV, Marshall CT, Yaragina NA (2003) Tracking the signal in year-class strength of Northeast Arctic cod through multiple survey estimates of egg, larval and juvenile abundance. J Sea Res 50:57-75

Nesterova VN (1990) Plankton biomass along the drift route of cod larvae (reference material). Technical report, PINRO, Murmansk

Neuheimer AB, MacKenzie BR, Payne MR (2018) Temperature-dependent adaptation allows fish to meet their food across their species' range. Sci Adv 4:eaar4349

Orlova E, Boitsov V, Nesterova V (2010) The influence of hydrographic conditions on the structure and functioning of the trophic complex plankton-pelagic fishes-cod. Polar Research Institute of Marine Fisheries and Oceanography (PINRO), Murmansk

Perry RI, Cury P, Brander K, Jennings S, Möllmann C, Planque B (2010) Sensitivity of marine systems to climate and fishing: concepts, issues and management responses. J Mar Syst 79:427-435

Planque B, Fromentin JM, Cury P, Drinkwater KF, Jennings S, Perry RI, Kifani S (2010) How does fishing alter marine populations and ecosystems sensitivity to climate? J Mar Syst 79:403-417

Platt T, Sathyendranath S (2008) Ecological indicators for the pelagic zone of the ocean from remote sensing. Remote Sens Environ 112:3426-3436

Platt T, Fuentes-Yaco C, Frank KT (2003) Marine ecology: spring algal bloom and larval fish survival. Nature 423: 398-399

R Core Team (2019) R: a language and environment for statistical computing. $\mathrm{R}$ Foundation for Statistical Computing, Vienna

Editorial responsibility: Franz Mueter, Juneau, Alaska, USA
Rolinski S, Horn H, Petzoldt T, Paul L (2007) Identifying cardinal dates in phytoplankton time series to enable the analysis of long-term trends. Oecologia 153:997-1008

* Rowlands WL, Dickey-Collas M, Geffen AJ, Nash RDM (2006) Gape morphology of cod Gadus morhua L., haddock Melanogrammus aeglefinus (L.) and whiting Merlangius merlangus (L.) through metamorphosis from larvae to juveniles in the western Irish Sea. J Fish Biol 69: 1379-1395

Sakshaug E, Johnsen GH, Kovacs KM (2009) Ecosystem Barents Sea. Tapir Academic Press, Trondheim

* Shepherd JG, Cushing DH (1980) A mechanism for densitydependent survival of larval fish as the basis of a stockrecruitment relationship. ICES J Mar Sci 39:160-167

Siegel DA, Doney SC, Yoder JA (2002) The North Atlantic spring phytoplankton bloom and Sverdrup's critical depth hypothesis. Science 296:730-733

Stige LC, Dalpadado P, Orlova E, Boulay AC, Durant JM, Ottersen G, Stenseth NC (2014) Spatiotemporal statistical analyses reveal predator-driven zooplankton fluctuations in the Barents Sea. Prog Oceanogr 120: 243-253

Stige LC, Langangen $\varnothing$, Yaragina NA, Vikebø FB and others (2015) Combined statistical and mechanistic modelling suggests food and temperature effects on survival of early life stages of Northeast Arctic cod (Gadus morhua). Prog Oceanogr 134:138-151

Stige LC, Yaragina NA, Langangen $\varnothing$, Bogstad B, Stenseth NC, Ottersen G (2017) Effect of a fish stock's demographic structure on offspring survival and sensitivity to climate. Proc Natl Acad Sci USA 114:1347-1352

Trippel EA, Kjesbu OS, Solemdal P (1997) Effects of adult age and size structure on reproductive output in marine fishes. In: Chambers RC, Trippel EA (eds) Early life history and recruitment in fish populations. Springer, Dordrecht, p 31-62

Varpe $\varnothing$, Fiksen $\varnothing$ (2010) Seasonal plankton-fish interactions: light regime, prey phenology, and herring foraging. Ecology 91:311-318

* Vikebø FB, Jørgensen C, Kristiansen T, Fiksen Ø (2007) Drift, growth, and survival of larval Northeast Arctic cod with simple rules of behaviour. Mar Ecol Prog Ser 347: 207-219

Wood SN (2017) Generalized additive models: an introduction with R, 2nd edn. CRC Press, Boca Raton, FL

* Yoder JA, Kennelly MA (2003) Seasonal and ENSO variability in global ocean phytoplankton chlorophyll derived from 4 years of SeaWiFS measurements. Global Biogeochem Cycles 17:1112

Submitted: October 17, 2019; Accepted: February 26, 2020 Proofs received from author(s): April 1, 2020 